\title{
Low fruit consumption and omission of daily meals as risk factors for increased blood pressure in adults
}

\author{
Talita Barbosa Domingos ${ }^{1}$, Avany Fernandes Pereira ${ }^{1}$, Edna Massae Yokoo $^{2}$ and Rosana Salles-Costa ${ }^{1 *}$ \\ ${ }^{1}$ Instituto de Nutrição Josué de Castro, Universidade Federal do Rio de Janeiro, Av. Carlos Chagas Filho 373, Edifício do Centro \\ de Ciências da Saúde, Bloco J, $2^{\circ}$ andar, Cidade Universitária, Rio de Janeiro, CEP 21941-902, Brazil \\ ${ }^{2}$ Instituto de Saúde Coletiva, Universidade Federal Fluminense, Rua Marques de Paraná, 303, $3^{\circ}$ andar, prédio anexo, Centro, \\ 24030-210, Niterói, Rio de Janeiro, Brazil
}

(Submitted 19 January 2016 - Final revision received 11 May 2016 - Accepted 20 May 2016 - First published online 20 June 2016)

\section{Abstract}

A population-based cross-sectional survey with cluster sampling design and with inverse sampling was conducted in 2010, in a sample of 1590 adults (19-60 years old) exposed to a high prevalence of food insecurity, in the municipality of Duque de Caxias, metropolitan region of Rio de Janeiro, Brazil. The objective of the study was to evaluate the association of socio-demographic factors, the consumption of fruits and vegetables and the number of meals with increased blood pressure (BP). A hierarchical model that considered variables related to the basic, intermediate and immediate determinants of increased BP was adopted. By using Poisson's regression, univariate models were tested to obtain the prevalence ratio (PR) and its respective 95\% CI. After fitting the model, age (age group 50-59 years) (PR 1.62; 95\% CI 1.09, 2.41), low consumption of fruits in a week (PR 1.37; $95 \%$ CI 1.07, 1.74), fewer meals per day (PR 1.72; 95\% CI 1.21, 2.43) and overweight (PR 1.78; $95 \%$ CI 1.31 2.20) remained significantly associated with increased BP. Therefore, the results found here reinforce the importance of encouraging and developing strategies that ensure access to healthy foods to minimise increased BP in similar populations.

Key words: Blood pressure: Overweight: Meals: Fruit intake

Hypertension is characterised as a multifactorial clinical condition in which blood pressure (BP) levels are persistently high. Currently, the condition is one of the leading causes of death and disability in the world, constituting a serious public health problem ${ }^{(1,2)}$. It is estimated that approximately $25 \%$ of the world's population is hypertensive and that the number of cases will increase by $60 \%$ by $2025^{(3)}$. In Brazil, the TelephoneBased Surveillance of Risk and Protective Factors for Chronic Diseases study observed hypertension in $24.1 \%$ of the adult population in $2014^{(4)}$.

According to the Brazilian Society of Hypertension ${ }^{(2)}$, genetic factors, age, sex, ethnicity, overweight and obesity, Na intake, alcohol consumption, physical inactivity and socio-economic factors are the main factors associated with increased BP levels. In the past decade, studies have revealed new evidence of the participation of dietary patterns of the population as potential risk and protective factors in the genesis of hypertension, especially the consumption of fruits and vegetables and daily meal frequency ${ }^{(5,6)}$.

Adequate consumption of fruits and vegetables leads to decreasing BP levels because of their high concentration of minerals with hypotensive potential (particularly $\mathrm{Mg}$ and $\mathrm{K}$ ) and low fat content ${ }^{(7)}$, which contributes to the reduction of both systolic and diastolic blood pressure (SBP and DBP, respectively $)^{(8)}$. Studies associate the habit of skipping meals with increased serum cholesterol, TAG, fasting glucose and insulin concentration $^{(9,10)}$, but studies on the subject are scarce.

The present study was conducted in a low-income population with a high prevalence of food insecurity (FI) ${ }^{(11)}$, which, in turn, contributes to a lower consumption of fruits and vegetables $^{(12)}$ when compared with higher-income populations. Thus, a dietary pattern that includes skipped meals and a low consumption of fruits and vegetables, resulting not only from the diet composition but also from difficult access to food, may be even more damaging ${ }^{(13)}$. Studies show that FI has repercussions on the prevalence of chronic diseases related to nutrition, including diabetes mellitus, hypertension and obesity $^{(14,15)}$. Thus, the objective of the present study was to evaluate the association of socio-demographic factors, the consumption of fruits and vegetables and the number of meals with increased BP in a population exposed to FI.

\section{Methods}

The present study is a population-based cross-sectional survey that was conducted in the municipality of Duque de Caxias

Abbreviations: BP, blood pressure; FI, food insecurity.

* Corresponding author: R. Salles-Costa, email rosana@nutricao.ufrj.br 
( $467619 \mathrm{~km}^{2}$ area), located in the metropolitan region of Rio de Janeiro. The second district of Duque de Caxias (Campos Elíseos) was selected for the present study because it is one of the poorest districts in the municipality.

A cluster sampling design was used in the present study, with inverse sampling, considering three selection stages (census sectors, private permanent housing and individuals). The sample size consisted of 1125 households from the second district of the municipality of Duque de Caxias, based on the prevalence of extreme poverty in the municipality of $14.5 \%{ }^{(16)}$. Thus, a sample of at least 1000 households would ensure obtaining estimates for proportions with $5 \%$ significance levels. In the first stage, of the total 322 district sectors, seventy-five were selected by systematic selection with probabilities proportional to the size of the geographic operational base (Base Operacional Geográfica) of 2000 of the Brazilian Institute of Geography and Statistics (Instituto Brasileiro de Geografia e Estatística (IBGE)). This method ensured representation by income, age group (children from 6 to 30 months and adolescents from 12 to 18 years of age) and sex stratum. In the second selection stage, fifteen households were randomly selected using an inverse sampling procedure ${ }^{(17)}$. This consists of specifying a number of interviews set in advance rather than the total number of households to be sampled. The procedure allowed checking how many $(n)$ units should be observed to obtain ( $k$ ) successful interviews. In the present study, this ensured sampling a sufficient number of households with children aged between 6 and 36 months. The third selection stage included individuals from each household to be surveyed. Adults aged between 19 and 60 years, excluding bedridden individuals and pregnant/lactating women, were eligible.

The data were collected from April to December 2010 by a team of twelve interviewers, which included four registered dietitian nutritionists (RDN) who were properly trained for this function. In total, the interviewers received $40 \mathrm{~h}$ of training in questionnaire application, assessment of food consumption and the measurement of anthropometric measures and BP.

\section{Study variables}

Data were collected using a questionnaire with questions on socio-demographic factors and lifestyle habits, and anthropometric assessment was performed.

BP was measured using an Automatic Blood Pressure Monitor Omron ${ }^{\circledR}$ (model HEM-7113 INT; Healthcare), which met the European Society of Hypertension standards for accuracy and performance. The measurement protocol included two measurements per individual. BP measurements were evaluated by the RDN at the end of the questionnaire application and before the anthropometrics measurements (almost $30 \mathrm{~min}$ after the interviewers arrived at the house of each family). The adult received general information about the $\mathrm{BP}$ procedure, was invited to remain seated in a comfortable position and drinking and smoking was not allowed; the adult was asked to rest for 5 min before the first measure, and measurements were taken without clothing, because it might interfere with the BP cuff or constrict blood flow in the arm. The BP cuff was placed on the patient's arm and the brachial artery was located to position the BP cuff; we chose the proper cuff size. RDN inflated the BP cuff until $30-40 \mathrm{mmHg}$ above the person's normal BP. If a difference $>10 \mathrm{mmHg}$ was found between the two measurements, a third measurement was performed after $20 \mathrm{~min}$ of rest, and the first measurement was discarded for analysis purposes. The mean of the two measurements was considered in the analyses. The cut-off points recommended by the Brazilian Society of Hypertension were used, and individuals with $\mathrm{SBP} \geq 140 \mathrm{mmHg}$ and/or $\mathrm{DBP} \geq 90 \mathrm{mmHg}$ were considered to have increased BP, which was analysed as a dichotomous variable (the presence or absence of increased BP).

Body weight was measured using a portable $\mathrm{G}-\mathrm{Tech}^{\circledR}$ electronic scale (with a $150 \mathrm{~kg}$ capacity and an accuracy within $100 \mathrm{~g}$; G Tech Scales \& Systems), and height was assessed with a portable $\mathrm{WCS}^{\circledR}$ vertical anthropometer (with a 0-220 cm range and an accuracy within $1 \mathrm{~mm}$; Wood Compact Stadiometer; Cardiomed). For the anthropometric measurements, the adults were informed to wear light clothes (shorts and T-shirts) and to remain barefoot during this stage. The measurements were performed by trained $\mathrm{RDN}$ according to the procedures described by Lohman et $a l .^{(18)}$. BMI was estimated from the body weight and height values, and the classification proposed by the World Health Organization ${ }^{(19)}$ was considered when estimating adequate body weights.

To evaluate the influence of socio-demographic indicators and lifestyle habits on increased BP, a hierarchical model of determinants of increased BP was used in three explanatory levels: the basic determinants (1st level), the intermediate determinants (2nd level) and the immediate determinant (3rd level), as shown in Fig. 1. The basic determinants considered were the following factors: age ${ }^{(20)}(<30,30-39$, $40-49,50-59$ years); race/ethnicity ${ }^{(21)}$ (white and black/mulatoes based on self-classification according to IBGE categories); marital status ${ }^{(20)}$ (married or single/separated/divorced); educational level $^{(22)}$ ( $\leq 9$ years of study, >9 years of study); monthly household per capita income ${ }^{(23)}$ (total household income divided by the number of residents who depend on this income, categorised into income thirds based on the 2010 monthly minimum wage, in dollars); economic classification of the families ${ }^{(24)}$ (according to the Socio-economic Scale of the Brazilian Association of Market Research; Associação Brasileira de Pesquisa de Mercados) ${ }^{(25)}$ (considering the educational level of the head of the household and the number of household appliances, vehicles, bathrooms and domestic workers); and the consumption of potable water (presence/ absence of water filters in households).

The intermediate determinants considered were as follows: the FI level of families, estimated by the Brazilian Household Food Insecurity Measurement Scale (Escala Brasileira de Medida Domiciliar de Insegurança Alimentar) ${ }^{(26)}$ (categorised into food security, mild insecurity and moderate and severe insecurity); smoking ${ }^{(27)}$ (individuals who smoked up to 100 cigarettes over a lifetime); consumption of alcohol ${ }^{(28)}$ (consumption of any beverage containing alcohol in the last year, including beer, wine, cachaça (distilled spirit made from sugar-cane juice), whisky or caipirinha (Brazilian drink made with cachaça and fruits), analysed as a dichotomous variable; consumption of fruits (consumption of fruits not in the form of 


\begin{tabular}{|c|}
\hline High blood pressure \\
\hline 4 \\
\hline Immediate determinant (3rd level) \\
\hline Overweight \\
\hline 4 \\
\hline Intermediate determinants (2nd level) \\
\hline Food insecurity level \\
\hline Smoking \\
\hline Consumption of alcohol \\
\hline Consumption of fruits and vegetables \\
\hline Number of daily meals \\
\hline$\hat{T}$ \\
\hline Basic determinants (1st level) \\
\hline Age \\
\hline Skin colour \\
\hline Marital status \\
\hline Educational level \\
\hline Monthly household per capita income \\
\hline Economic classification of the families \\
\hline Consumption of potable water \\
\hline
\end{tabular}

Fig. 1. Hierarchial model of determinants of increased blood pressure among adults (Duque de Caxias/Rio de Janeiro, Brazil, 2010).

juices and soft drinks) and vegetables (consumption of vegetables other than potatoes, yams and cassava or other roots, at least five times per week (yes/no)); and the number of daily meals (breakfast, lunch, snack and dinner, dividing the number of total meals into three categories: up to two, three or four meals per day). In the last level, overweight (BMI $\geq 25 \mathrm{~kg} / \mathrm{m}^{2}$ ) was considered.

\section{Statistical analysis}

For the statistical analysis, the percentage distribution and 95\% CI were estimated according to the categories of each study variable. A hierarchical model that considered variables related to the basic, intermediate and immediate determinants of increased BP was adopted. By using Poisson's regression, univariate models were tested to obtain the prevalence ratio (PR) and its respective $95 \%$ CI. Variables with $P$-values $<0 \cdot 20$ were included in the multivariate analysis at each hierarchical level, and the models were fitted at each subsequent level, by keeping those variables in the models that were significantly associated at the $5 \%$ significance level with the outcome of increased BP. The final hierarchical model was obtained by considering the fit of the variables at the three levels (adjusted $\mathrm{PR})$. The parameters and respective $95 \%$ CI were estimated for the expanded data, considering the cluster sampling design effect.

A database was created using CSPro $2.3^{(29)}$, and the data were doubly entered for quality control purposes. All of the analysis procedures were performed in Stata $13^{(30)}$.

All participants were informed about the ethical aspects of the study and were asked to sign the study's consent form before the interviews. The present study was approved by the Ethics in Research Committee of the Rio de Janeiro State University (Universidade do Estado do Rio de Janeiro) (process number 73/2009).

\section{Results}

The final sample consisted of 1121 households from which 1549 adults were interviewed. Of these, $50 \cdot 8 \%$ were men and $49.2 \%$ were women, $29 \cdot 1 \%$ exhibited increased BP and the most prevalent age group was 30-39 years (37.2\%). There was a predominance of adults who self-classified as black/mulatoes (66.4\%), married or cohabiting (74.4\%) and with 9-11 years of education $(37 \cdot 1 \%)$. The predominant monthly household per capita income, considering multiples of the minimum wage, ranged from half to one monthly minimum wage for $39.8 \%$ of the individuals evaluated, and the monthly minimum wage in 2010 was 510.00 Brazilian real. The 3rd level of economic classification (level ' $\mathrm{C}$ ') was the most prevalent (70.6\%); FI was found in approximately half of the households (31.7\% mild FI and $10.4 \%$ moderate/severe FI), and the consumption of potable water was found in more than twothirds of the households. With regard to lifestyle habits, $19 \cdot 5 \%$ were smokers, $35.4 \%$ of the adults (men and women) consumed alcoholic beverages, 45.2 and $32.4 \%$ did not consume fruits and vegetables regularly, respectively, and $31 \% \mathrm{had}$ up to three meals per day (9\% up to two meals and $22 \%$ up to three meals). Of the evaluated individuals, $62.5 \%$ were overweight (Table 1).

When assessing the relationship between the study variables and increased BP, age, education and FI were the sociodemographic factors that were significantly associated with increased BP. Among the variables related to lifestyle habits, there was a significant association of fruit consumption, daily meals and overweight with increased BP (Table 2).

Considering the hierarchical model used to evaluate the effect of the study variables on increased BP, the results of the univariate analysis showed that, among the basic determinants, the eldest adults, those who self-classified as black and brown, those from families with moderate to severe FI, those with lower educational levels and those from economic classes D and $\mathrm{E}$ were associated with increased BP. Among the intermediate determinants, adults who reported consuming alcoholic beverages, not consuming fruits and having fewer meals per day (less than four meals) were associated with increased BP (Table 3). Overweight, which was an immediate determinant evaluated in the present study, was also associated with increased BP. After fitting the model, age (age group 50-59 years), low consumption of fruits in a week, fewer meals 
Table 1. Prevalence ratio (\%) and $95 \% \mathrm{Cl}$ of high blood pressure, sociodemographic characteristics, lifestyle habits and overweight among adults (Duque de Caxias/Rio de Janeiro, Brazil, 2010)

(Prevalence ratio and $95 \%$ confidence intervals)

\begin{tabular}{|c|c|c|}
\hline Variables* & Prevalence ratio (\%) & $95 \% \mathrm{Cl}$ \\
\hline \multicolumn{3}{|l|}{ High blood pressure $(n$ 1454)† } \\
\hline Yes & 29.1 & $25 \cdot 8,32 \cdot 5$ \\
\hline No & 70.9 & $67 \cdot 4,74 \cdot 1$ \\
\hline \multicolumn{3}{|l|}{ Socio-demographic characteristics } \\
\hline \multicolumn{3}{|l|}{ Sex $(n 1529)$} \\
\hline Male & $50 \cdot 8$ & $47 \cdot 3,54 \cdot 4$ \\
\hline Female & $49 \cdot 2$ & $45 \cdot 6,52 \cdot 7$ \\
\hline \multicolumn{3}{|l|}{ Age (years) $(n 1529)$} \\
\hline$<30$ & 21.4 & $18 \cdot 5,24 \cdot 5$ \\
\hline $30-39.9$ & $37 \cdot 2$ & $33.7,40.9$ \\
\hline $40-49.9$ & $22 . \overline{4}$ & $19 \cdot 8,25 \cdot 3$ \\
\hline $50-59 \cdot 9$ & $19 \cdot 0$ & $16 \cdot 5,21 \cdot 6$ \\
\hline \multicolumn{3}{|l|}{ Race/ethnicity ( $n$ 1461) } \\
\hline Black/mulatoes & $66 \cdot 4$ & $62 \cdot 8,69 \cdot 8$ \\
\hline White & 33.6 & $30 \cdot 2,37 \cdot 2$ \\
\hline \multicolumn{3}{|l|}{ Marital status ( $n$ 1522) } \\
\hline Married & 74.4 & $71 \cdot 0,77 \cdot 6$ \\
\hline Single/separated/divorced & 25.6 & $22 \cdot 4,29 \cdot 0$ \\
\hline \multicolumn{3}{|c|}{ Monthly household per capita income $(n$ 1489) } \\
\hline 1st tercile & $27 \cdot 2$ & $24 \cdot 1,30 \cdot 4$ \\
\hline 2nd tercile & $32 \cdot 6$ & $29 \cdot 2,36 \cdot 2$ \\
\hline 3rd tercile & $40 \cdot 2$ & $36 \cdot 7,43.8$ \\
\hline \multicolumn{3}{|c|}{ Economic classification§ ( $n$ 1470) } \\
\hline$A / B$ & $13 \cdot 3$ & $11 \cdot 1,15 \cdot 8$ \\
\hline C & $70 \cdot 6$ & $67 \cdot 2,73 \cdot 7$ \\
\hline $\mathrm{D} / \mathrm{E}$ & $16 \cdot 1$ & $13.6,18.9$ \\
\hline \multicolumn{3}{|l|}{ FIII $(n$ 893) } \\
\hline Food security & 57.9 & $53 \cdot 2,62 \cdot 4$ \\
\hline Mild FI & 31.7 & $27 \cdot 5,36 \cdot 1$ \\
\hline Severe/moderate FI & $10 \cdot 4$ & $7.9,13.5$ \\
\hline \multicolumn{3}{|c|}{ Consumption of potable water $(n 1381)$} \\
\hline Yes & $77 \cdot 2$ & $74.0,80 \cdot 2$ \\
\hline No & $22 \cdot 7$ & $19 \cdot 7,25 \cdot 9$ \\
\hline \multicolumn{3}{|l|}{ Lifestyle habits } \\
\hline \multicolumn{3}{|l|}{ Current smoker| (n 1521) } \\
\hline Yes & 19.5 & $16 \cdot 8,22 \cdot 4$ \\
\hline No & 80.5 & $77.5,83.2$ \\
\hline \multicolumn{3}{|c|}{ Consumption of alcohol** $(n$ 1521) } \\
\hline Yes & 35.4 & $31.9,38.9$ \\
\hline No & 64.6 & $61.0,68.0$ \\
\hline \multicolumn{3}{|l|}{ Fruit intake†† ( $n$ 1521) } \\
\hline Yes & $54 \cdot 8$ & $51 \cdot 2,58 \cdot 3$ \\
\hline No & 45.2 & $41 \cdot 6,48 \cdot 8$ \\
\hline \multicolumn{3}{|l|}{ Vegetable intake执 $(n$ 1528) } \\
\hline Yes & $67 \cdot 6$ & $64 \cdot 0,70 \cdot 9$ \\
\hline No & 32.4 & $29.0,35.9$ \\
\hline \multicolumn{3}{|l|}{ Number of daily meals $(n 1500)$} \\
\hline$\leq 2$ & 9.0 & $7 \cdot 1,11 \cdot 4$ \\
\hline$\overline{3}$ & $22 \cdot 0$ & $19 \cdot 2,25 \cdot 1$ \\
\hline$\geq 4$ & 69.0 & $65 \cdot 5,72 \cdot 2$ \\
\hline \multicolumn{3}{|l|}{ Overweight§§ ( $n$ 1529) } \\
\hline Yes & 62.5 & $58 \cdot 9,65 \cdot 8$ \\
\hline No & 37.5 & $34 \cdot 1,41 \cdot 0$ \\
\hline
\end{tabular}

$\mathrm{FI}$, food insecurity; USD, US dollars.

* The total values in each variable differ because of missing data.

$\dagger$ High blood pressure = individuals with systolic blood pressure $\geq 140 \mathrm{mmHg}$ and/or diastolic blood pressure $\geq 90 \mathrm{mmHg}$.

$\ddagger$ Monthly minimum wage $=$ at the USD-Brazilian real exchange rate of 1 July 2010 , monthly per capita income of 228.27 USD, estimated in terciles.

$\S$ According to the Socio-economic Scale of the Brazilian Association of Market Research ${ }^{(25)}$.

\| According to the Brazilian Household Food Insecurity Measurement Scale (Escala Brasileira de Medida Domiciliar de Insegurança Alimentar) ${ }^{(26)}$.

If Considering smokers as individuals who smoked up to 100 cigarettes over a lifetime.

** Consumption of any beverage containing alcohol in the last year, including beer, wine, cachaça (distilled spirit made from sugar-cane juice), whisky or caipirinha (Brazilian drink made with cachaça and fruits).

†† Consumption of fruits not in the form of juices and soft drinks at least five times per week.

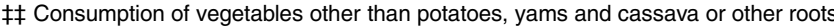
at least five times per week.

$\S \S \mathrm{BMI} \geq 25 \mathrm{~kg} / \mathrm{m}^{2}$. per day and overweight remained significantly associated with increased BP (Table 3).

\section{Discussion}

The present study found a prevalence of increased BP of $29 \cdot 1 \%$ in the studied population and also found that in addition to overweight age over 50 years and the consumption of fruits $<5$ d a week combined with fewer meals per day contributed to increased BP levels.

The association between age and BP corroborates findings from other studies that observed a direct and linear relationship between increased age and BP levels, particularly beginning at 60 years of age ${ }^{(31)}$. In a cross-sectional study conducted with approximately 5000 individuals between 20 and 60 years of age from the urban area of the cities of Paraná State, Brazil, it was observed that adults over 40 years of age of both sexes exhibited an increased prevalence of hypertension ${ }^{(32)}$. With regard to the relationship between fruit consumption and increased BP, the results of the final fitted model showed that among adults who consumed fruits less than five times per week, the PR of increased BP was $45 \%$ higher compared with adults who consumed fruits more often. The mechanism by which fruit consumption leads to decreased $\mathrm{BP}$ is complex because of the presence of minerals such as $\mathrm{K}, \mathrm{Mg}$ and $\mathrm{Ca}$, which have a hypotensive effect related to vasodilation and increased natriuresis ${ }^{(7,33,34)}$. The effect of diet on BP variation was evaluated by comparing a diet with a low content of fruits, vegetables and dairy products and with a fat content typical of the diet of Americans (control) with a diet rich in fruits and vegetables ${ }^{(7)}$. At the end of the study, those authors observed that the diet rich in fruits and vegetables promoted a significant reduction of $2.8 \mathrm{mmHg}$ in SBP $(P$-value $<0.001)$ compared with the control diet. Similar results were observed by Miura et $a l .{ }^{(5)}$, in a prospective cohort study performed during 7 years of follow-up with male workers aged between 41 and 57 years from Chicago and other cities in Illinois. According to the authors, the infrequent consumption of fruits was associated with an increase in SBP and DBP over time, regardless of age, body weight and consumption of other types of food.

With regard to possible factors associated with the lower inclusion of fruits in the diet of the evaluated adults, it should be emphasised that food choices are complex decisions influenced both by biological factors and by social, cultural and economic factors. Thus, the importance of the monthly household per capita income and food prices as a decisive factor on the consumption of fruits and vegetables should be noted. Studies conducted in developed countries indicate that fruits and vegetables increase family expenses because of their high cost and that economic restrictions favour diets with low contents of fruits and vegetables and high energy density ${ }^{(35-37)}$. Thus, Brazilian studies show that the decrease in the price of fruits and vegetables and the increase in the minimum wage have contributed to greater amounts of fruits and vegetables in the total food purchased by families ${ }^{(38)}$. Although vegetables and fruits may be more expensive than some highly processed foods, the total cost of food based on fresh or minimally processed food is still lower in Brazil ${ }^{(39)}$. 
Table 2. Proportion (\%) and $95 \% \mathrm{Cl}$ about the relationship among socio-demographic indicators, lifestyle habits and overweight according to high blood pressure (Duque de Caxias/Rio de Janeiro, Brazil, 2010)

(Proportion (\%) and 95\% confidence intervals)

\begin{tabular}{|c|c|c|c|c|c|}
\hline \multirow[b]{3}{*}{ Variables* } & \multicolumn{5}{|c|}{ High blood pressure† } \\
\hline & \multicolumn{2}{|c|}{ Yes } & \multicolumn{2}{|c|}{ No } & \multirow[b]{2}{*}{$P$} \\
\hline & Proportion (\%) & $95 \% \mathrm{Cl}$ & Proportion (\%) & $95 \% \mathrm{Cl}$ & \\
\hline \multicolumn{6}{|l|}{ Socio-demographic indicators } \\
\hline $\operatorname{Sex}(n$ 1529) & & & & & 0.89 \\
\hline Male & 49.7 & $42 \cdot 8,56 \cdot 5$ & $50 \cdot 2$ & $45 \cdot 9,54.5$ & \\
\hline Female & $50 \cdot 3$ & $43 \cdot 4,57 \cdot 1$ & 49.8 & $45 \cdot 4,54 \cdot 1$ & \\
\hline Age (years) $(n 1529)$ & & & & & $<0.001$ \\
\hline$<30$ & $14 \cdot 3$ & $9 \cdot 8,20 \cdot 2$ & 24.5 & $20 \cdot 9,28.5$ & \\
\hline $30-39.9$ & 33.9 & $27 \cdot 3,41 \cdot 2$ & 37.1 & $32 \cdot 8,41 \cdot 4$ & \\
\hline $40-49.9$ & $24 \cdot 3$ & $19 \cdot 3,30 \cdot 0$ & $22 \cdot 1$ & $18 \cdot 9,25 \cdot 6$ & \\
\hline $50-59 \cdot 9$ & 27.5 & $22 \cdot 2,33 \cdot 5$ & $16 \cdot 3$ & $13 \cdot 6,19.4$ & \\
\hline Race/ethnicity ( $n$ 1461) & & & & & 0.06 \\
\hline Black/mulatoes & 61.4 & $54 \cdot 3,68 \cdot 1$ & 68.8 & $64 \cdot 5,72 \cdot 7$ & \\
\hline White & 38.6 & $31.9,45.6$ & 31.2 & $27 \cdot 2,35 \cdot 5$ & \\
\hline Marital status ( $n$ 1522) & & & & & 0.74 \\
\hline Married & $75 \cdot 1$ & $68 \cdot 7,80 \cdot 5$ & 73.9 & $69 \cdot 5,77 \cdot 8$ & \\
\hline Single/separated/divorced & 24.9 & $19 \cdot 4,31 \cdot 2$ & $26 \cdot 1$ & $22 \cdot 2,30 \cdot 4$ & \\
\hline Educational level (years) ( $n$ 1501) & & & & & 0.14 \\
\hline$\leq 9$ & $36 \cdot 4$ & $30 \cdot 0,43 \cdot 1$ & $30 \cdot 6$ & $26 \cdot 7,34.8$ & \\
\hline$>9$ & 63.6 & $56 \cdot 8,70 \cdot 0$ & $69 \cdot 3$ & $65 \cdot 2,73 \cdot 2$ & \\
\hline Monthly household per capita income $\neq$ ( $n$ 1489) & & & & & 0.60 \\
\hline 1st tercile & 24.4 & $19 \cdot 5,30.2$ & 27.4 & $23 \cdot 7,31 \cdot 4$ & \\
\hline 2nd tercile & 34.8 & $28 \cdot 4,41 \cdot 7$ & 31.4 & $27 \cdot 4,35 \cdot 7$ & \\
\hline 3rd tercile & $40 \cdot 8$ & $34 \cdot 0,47 \cdot 8$ & 41.2 & $37 \cdot 0,45 \cdot 6$ & \\
\hline Economic classification $\S(n$ 1470) & & & & & 0.11 \\
\hline $\mathrm{A} / \mathrm{B}$ & $12 \cdot 4$ & $8 \cdot 3,18 \cdot 0$ & 13.7 & $11 \cdot 2,16 \cdot 7$ & \\
\hline C & $66 \cdot 7$ & $59 \cdot 8,72 \cdot 8$ & 71.8 & $67 \cdot 7,75.5$ & \\
\hline $\mathrm{D} / \mathrm{E}$ & 20.9 & $15 \cdot 9,26 \cdot 9$ & 14.5 & $11.5,17.9$ & \\
\hline FIII $(n$ 893) & & & & & $<0.05$ \\
\hline Food security & $57 \cdot 1$ & $50 \cdot 1,63.8$ & 59.4 & $54.9,63 \cdot 7$ & \\
\hline Mild FI & 28.0 & $22 \cdot 3,34 \cdot 4$ & 32.5 & $28 \cdot 3,36 \cdot 7$ & \\
\hline Severe/moderate FI & 14.9 & $10.5,20 \cdot 6$ & $8 \cdot 1$ & $6 \cdot 0,10 \cdot 7$ & \\
\hline Consumption of potable water ( $n$ 1381) & & & & & 0.28 \\
\hline Yes & 74.1 & $67 \cdot 3,79.9$ & 78.0 & $74 \cdot 0,81 \cdot 4$ & \\
\hline No & $25 \cdot 9$ & $20 \cdot 0,32 \cdot 6$ & $22 \cdot 0$ & $18.5,25 \cdot 9$ & \\
\hline Lifestyle habits & & & & & \\
\hline Current smoker- ( $n$ 1521) & & & & & 0.24 \\
\hline Yes & $22 \cdot 1$ & $16 \cdot 9,28 \cdot 4$ & 18.4 & $15 \cdot 3,21 \cdot 8$ & \\
\hline No & 77.9 & $71 \cdot 5,83 \cdot 1$ & $81 \cdot 6$ & $78 \cdot 5,84 \cdot 6$ & \\
\hline Consumption of alcohol** $(n$ 1521) & & & & & 0.39 \\
\hline Yes & 37.9 & $31 \cdot 3,44 \cdot 8$ & 34.5 & $30 \cdot 4,38 \cdot 8$ & \\
\hline No & $62 \cdot 1$ & $55 \cdot 1,68 \cdot 2$ & 65.5 & $61 \cdot 2,69 \cdot 6$ & \\
\hline Fruit intake†† ( $n$ 1521) & & & & & $<0.01$ \\
\hline Yes & $46 \cdot 2$ & $39 \cdot 4,53 \cdot 1$ & $58 \cdot 2$ & $53 \cdot 8,62 \cdot 3$ & \\
\hline No & 53.8 & $46 \cdot 9,60 \cdot 5$ & 41.8 & $37 \cdot 6,46 \cdot 2$ & \\
\hline Vegetable intake $\ddagger \ddagger$ ( $n$ 1528) & & & & & 0.70 \\
\hline Yes & $66 \cdot 6$ & $59 \cdot 8,72 \cdot 8$ & $68 \cdot 1$ & $63 \cdot 8,72 \cdot 1$ & \\
\hline No & $33 \cdot 3$ & $27 \cdot 1,40 \cdot 1$ & 31.9 & $27 \cdot 8,36 \cdot 1$ & \\
\hline Number of daily meals ( $n$ 1500) & & & & & $<0.001$ \\
\hline$\leq 2$ & $14 \cdot 0$ & $9 \cdot 8,19.4$ & $7 \cdot 1$ & $5.0,9.9$ & \\
\hline 3 & 28.6 & $22 \cdot 8,35 \cdot 1$ & $19 \cdot 0$ & $15 \cdot 8,22 \cdot 4$ & \\
\hline$\geq 4$ & 57.4 & $50.5,64.0$ & 73.9 & $69 \cdot 9,77 \cdot 6$ & \\
\hline Overweight§§ ( $n$ 1529) & & & & & $<0.001$ \\
\hline Yes & $72 \cdot 9$ & $66.5,78.4$ & $57 \cdot 3$ & $52 \cdot 9,61 \cdot 5$ & \\
\hline No & $27 \cdot 1$ & $21.5,33.4$ & $42 \cdot 7$ & $38 \cdot 4,47 \cdot 1$ & \\
\hline
\end{tabular}

FI, food insecurity

* The total values of each variable differ because of missing data.

† High blood pressure $=$ individuals with systolic blood pressure $\geq 140 \mathrm{mmHg}$ and/or diastolic blood pressure $\geq 90 \mathrm{mmHg}$.

$\ddagger$ Monthly minimum wage $=$ at the USD-Brazilian real exchange rate of 1 July 2010, monthly per capita income of 228.27 USD, estimated in terciles.

$\S$ According to the Socio-economic Scale of the Brazilian Association of Market Research ${ }^{(25)}$.

$\|$ According to the Brazilian Household Food Insecurity Measurement Scale (Escala Brasileira de Medida Domiciliar de Insegurança Alimentar) ${ }^{\text {(26) }}$

I Considering smokers as individuals who smoked up to 100 cigarettes over a lifetime.

** Consumption of any beverage containing alcohol in the last year, including beer, wine, cachaça (distilled spirit made from sugar-cane juice), whisky or caipirinha (Brazilian drink made with cachaça and fruits).

t† Consumption of fruits not in the form of juices and soft drinks at least five times per week.

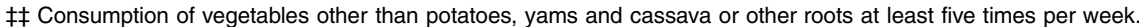

$\S \S \mathrm{BMI} \geq 25 \mathrm{~kg} / \mathrm{m}^{2}$. 
Table 3. Prevalence ratio (PR) and $95 \% \mathrm{Cl}$ of the association between hierarchical levels and high blood pressure (Duque de Caxias/Rio de Janeiro, Brazil, 2010) (Prevalence ratios and $95 \%$ confidence intervals)

\begin{tabular}{|c|c|c|c|c|c|c|}
\hline & \multicolumn{6}{|c|}{ High blood pressure* } \\
\hline & \multicolumn{3}{|c|}{ Univariate models } & \multicolumn{3}{|c|}{ Adjusted models } \\
\hline & PR & $95 \% \mathrm{Cl}$ & $P$ & PR & $95 \% \mathrm{Cl}$ & $P$ \\
\hline \multicolumn{7}{|l|}{ Basic determinants } \\
\hline \multicolumn{7}{|l|}{ Sex } \\
\hline Male & 0.98 & $0.78,1 \cdot 24$ & 0.894 & & & \\
\hline Female & \multicolumn{3}{|c|}{ Ref. } & & & \\
\hline \multicolumn{7}{|l|}{ Age (years) } \\
\hline$<30$ & \multicolumn{3}{|c|}{ Ref. } & \multicolumn{2}{|c|}{ Ref. } & \\
\hline $30-39 \cdot 9$ & 1.41 & $0.93,2.15$ & 0.102 & 1.27 & $0.84,1.92$ & 0.253 \\
\hline $40-49.9$ & 1.61 & $1.07,2.41$ & 0.022 & 1.30 & $0.86,1.96$ & 0.203 \\
\hline $50-59 \cdot 9$ & $2 \cdot 12$ & $1.43,3.14$ & $<0.001$ & 1.62 & $1.09,2.41$ & 0.017 \\
\hline \multicolumn{7}{|l|}{ Race/ethnicity } \\
\hline Black/mulatoes & $0 \cdot 79$ & $0.62,1.01$ & 0.064 & & & \\
\hline White & \multicolumn{3}{|c|}{ Ref. } & & & \\
\hline \multicolumn{7}{|l|}{ Marital status } \\
\hline Married & 1.04 & $0.79,1.37$ & 0.742 & & & \\
\hline Single/separated/divorced & \multicolumn{3}{|c|}{ Ref. } & & & \\
\hline \multicolumn{7}{|l|}{ Educational level (years) } \\
\hline$<9$ & $1 \cdot 19$ & $0.94,1.51$ & 0.136 & & & \\
\hline$>9$ & \multicolumn{3}{|c|}{ Ref. } & & & \\
\hline \multicolumn{7}{|c|}{ Monthly household per capita income† } \\
\hline 1st tercile & 0.92 & $0.70,1 \cdot 23$ & 0.612 & & & \\
\hline 2nd tercile & \multirow{2}{*}{\multicolumn{3}{|c|}{ Ref. }} & & & \\
\hline 3rd tercile & & & & & & \\
\hline Economic classification $\ddagger$ & & & & & & \\
\hline $\mathrm{A} / \mathrm{B}$ & & & & & & \\
\hline C & 1.02 & $0.70,1.48$ & 0.912 & & & \\
\hline $\mathrm{D} / \mathrm{E}$ & 1.38 & $0.90,2 \cdot 10$ & $0 \cdot 130$ & & & \\
\hline $\mathrm{FI} \S$ & & & & & & \\
\hline Food security & & & & & & \\
\hline Mild FI & 0.92 & $0.70,1.21$ & 0.575 & 0.87 & $0.66,1.14$ & 0.314 \\
\hline Severe/moderate FI & 1.50 & $1 \cdot 10,2 \cdot 05$ & 0.009 & 1.23 & $0.92,1.66$ & 0.157 \\
\hline Consumption of potable wate & & & & & & \\
\hline Yes & & & & & & \\
\hline No & $1 \cdot 16$ & $0.88,1.51$ & 0.277 & & & \\
\hline Intermediate determinants & & & & & & \\
\hline Current smokerll & & & & & & \\
\hline Yes & 1.04 & $0.78,1.38$ & 0.774 & & & \\
\hline No & & & & & & \\
\hline Consumption of alcoholף & & & & & & \\
\hline Yes & $1 \cdot 20$ & $0.94,1.52$ & $0 \cdot 128$ & & & \\
\hline No & & & & & & \\
\hline Fruit intake ${ }^{\star \star}$ & & & & & & \\
\hline Yes & & & & & & \\
\hline No & 1.45 & $1 \cdot 14,1 \cdot 84$ & 0.002 & 1.37 & $1.07,1.74$ & 0.010 \\
\hline Vegetable intake†† & & & & & & \\
\hline Yes & & & & & & \\
\hline No & $1 \cdot 11$ & $0.86,1.43$ & 0.417 & & & \\
\hline Number of daily meals & & & & & & \\
\hline$\leq 2$ & 1.73 & $1 \cdot 25,2 \cdot 40$ & 0.001 & 1.72 & $1.21,2.43$ & 0.002 \\
\hline 3 & 1.53 & $1.18,1.99$ & 0.001 & 1.48 & $1 \cdot 15,2 \cdot 43$ & 0.002 \\
\hline$\geq 4$ & & & & & & \\
\hline Immediate determinants & & & & & & \\
\hline Overweightł‡ & & & & & & \\
\hline Yes & $1 \cdot 70$ & $1 \cdot 31,2 \cdot 20$ & $<0.001$ & $1 \cdot 70$ & $1 \cdot 31,2 \cdot 20$ & $<0.001$ \\
\hline No & & & & & & \\
\hline
\end{tabular}

Ref., referent values; Fl, food insecurity.

* High blood pressure = individuals with systolic blood pressure $\geq 140 \mathrm{mmHg}$ and/or diastolic blood pressure $\geq 90 \mathrm{mmHg}$.

† Monthly minimum wage $=$ at the USD-Brazilian real exchange rate of 1 July 2010, monthly per capita income of $228 \cdot 27$ USD, estimated in terciles.

$\mp$ According to the Socio-economic Scale of the Brazilian Association of Market Research ${ }^{(25)}$.

$\S$ According to the Brazilian Household Food Insecurity Measurement Scale (Escala Brasileira de Medida Domiciliar de Insegurança Alimentar) ${ }^{(26)}$.

॥ Considering smokers as individuals who smoked up to 100 cigarettes over a lifetime.

I Consumption of any beverage containing alcohol in the last year, including beer, wine, cachaça (distilled spirit made from sugar-cane juice), whisky or caipirinha (Brazilian drink made with cachaça and fruits).

** Consumption of fruits not in the form of juices and soft drinks at least five times per week

t† Consumption of vegetables other than potatoes, yams and cassava or other roots at least five times per week.

㧊 $\mathrm{BMl} \geq 25 \mathrm{~kg} / \mathrm{m}^{2}$. 
In fact, the high price of food was mentioned by the adults interviewed in the present study as one of the reasons that contributed to the infrequent consumption of fruits and vegetables (34.2\%) among individuals with increased BP (data not shown). Moreover, in the region in which the study was conducted, fairs and markets that sell good-quality fruits and vegetables are scarce; therefore, access to healthy food is difficult, which contributes to the increased costs of diets based on fruits and vegetables. In addition, the studied population had a high prevalence of FI, which is strongly associated with poverty ${ }^{(11)}$. Thus, it is important to encourage the consumption of fruits and vegetables along with policies to decrease their prices, such as access to foods from family farms.

The association between fewer daily meals with increased BP has been little explored in the literature. According to the results, individuals who reported consuming up to two meals per day were twice as likely to exhibit increased BP. Studies show that skipping meals is associated with being overweight ${ }^{(40)}$, which, in the present study, was also found to be a risk factor for increased BP. Thus, a potential hypothesis for the association between fewer meals and increased BP would be that these individuals are more susceptible to overweight and therefore to increased BP levels

The present study did not aim to evaluate specific meals but rather the number of daily meals. However, Holmbäck et al. ${ }^{(41)}$ suggest that, in general, a high eating frequency is associated with a healthy lifestyle. Currently, skipping breakfast is a well-studied factor and is related to diseases because the feeling of hunger and the desire to eat are classified as higher when skipping breakfast than when skipping other meals ${ }^{(42-44)}$. Thus, new analyses that allow identifying the skipped meal will be able to contribute to the discussion about the topic explored here.

A possible limitation of the present study is the fact that it did not estimate the dietary $\mathrm{Na}$ intake of the evaluated adults. However, analyses of data on the Brazilian population show that the average $\mathrm{Na}$ intake in the country is excessive and above the recommended values. When analysing the 2008/2009 Household Budget Survey (Pesquisa de Orçamentos Familiares (POF)) by food availability, Sarno et al. ${ }^{(45)}$ found that the daily amount of $\mathrm{Na}$ available for consumption in Brazilian households was $4.7 \mathrm{~g}$ for a daily intake of $8368 \mathrm{~kJ}$ (2000 kcal), which is more than twice the recommended limit. This excessive amount of available $\mathrm{Na}$ was found in all Brazilian macro-regions and income classes. Araujo et al. ${ }^{(46)}$ analysed data on individual food intake in Brazil (Brazilian National Food Survey (Inquérito Nacional de Alimentação)), also collected by POF (2008/2009), and found that inadequate and excessive $\mathrm{Na}$ intake (over $2300 \mathrm{mg}$ ) was reported in $89.3 \%$ of men and $70 \%$ of women. The analysis of isolated dietary $\mathrm{Na}$ intake is usually not considered in the analysis of dietary patterns because of the difficulty in accessing this information accurately, even if specific dietary survey methods are used. This challenge occurs because individuals find great difficulty in determining the amount of added $\mathrm{Na}$ used daily, and there is little information available on the content of $\mathrm{Na}$ in manufactured products. Even the method that is currently considered the gold standard to estimate $\mathrm{Na}$ intake has a number of limitations that compromise its use $e^{(47,48)}$.
Another limitation was the method used to evaluate the consumption of fruits and vegetables, which was based on the frequency of consumption levels. Although many studies use more objective methods, such as 24-h records and semiquantitative frequency questionnaires, there are many studies in the literature that use the frequency of consumption in their analyses, indicating that this is a valid assessment method that also allows accessing information on consumption and its possible interrelationships with health and disease processes $^{(49,50)}$

A further limitation point is physical activity, which was not considered in the analysis. In fact, low levels of physical activity increase the prevalence of hypertension ${ }^{(51)}$. Nevertheless, it should be noted that another study in the same population carried out by the same research group observed high prevalence of physical inactive activities in adults $(70 \%)^{(52)}$. It is noteworthy that since the previous survey was concluded (2010) it has not been observed local public policy investments or infrastructure facilities, which could increase engagement leisure-time on physical activities by this population; probably the high prevalence of physical inactive activities is the same. Thus, the non-inclusion of this variable in the analysis model, as potential confounder, probably would not change the results given the strong association of low fruit intake, number of daily meals and overweight with hypertension.

In the present study, unlike what was observed by Shariff et $a{ }^{(53)}$, FI was not associated with increased BP. A possible explanation for this lack of association is the fact that the population had a high prevalence of FI, which may have minimised the effect of FI on BP. However, for being a homogeneous population, even when faced with poverty, a situation in which social determinants lose their magnitude, the families that managed to include the consumption of fruits and vegetables associated with a greater number of daily meals could exhibit protection factors for increased BP.

In summary, an association between increased BP and age, infrequent consumption of fruits, skipping meals and overweight was observed in the present study. The population studied was a low-income population exposed to FI that did not have access to healthy foods, in terms of the consumption of fruits and vegetables and greater frequency of meals. Therefore, the results found here reinforce the importance of encouraging and developing strategies that ensure access to healthy foods to minimise increased $\mathrm{BP}$ in populations with similar socioeconomic conditions and with high level of FI as it was in the studied population.

\section{Acknowledgements}

The authors thank the Brazilian National Research Council (Conselho Nacional de Pesquisa (CNPq)) and Carlos Chagas Filho Research Support Foundation (Fundação Carlos Chagas de Apoio à Pesquisa do Estado do Rio de Janeiro (FAPERJ)) for support in this research.

This research was supported by the CNPq; grant number: Edital Universal 476344/2008-5) and FAPERJ; grants numbers: E-26/ $110 \cdot 785 / 2010$ and E-26/103.296/2011) for the research funding. 
T. B. D. participated in data analysis, the manuscript concept and writing; A. F. P. collaborated in writing the discussion and in revising the manuscript; E. M. Y. collaborated in data analysis, writing the discussion and revising the manuscript; R. S.-C. conceptualised the study, coordinated the research and financial support, and contributed to the writing and revision of the manuscript.

The authors declare that there are no conflicts of interest.

\section{References}

1. Malta DC, Moura L, Souza FM, et al. (2009) Chronic Non-Communicable Diseases and Association Factors in Brazil, 1990 to 2006, pp. 337-362. Brazil: Ministry of Health.

2. Brazilian Society of Hypertension (2010) VI Brazilian guidelines on hypertension. Arq Bras Cardiol 95, 1-51.

3. Kearney PM, Whelton M, Reynolds K, et al. (2005) Global burden of hypertension: analysis of worldwide data. Lancet 365, 217-223.

4. Vigitel Brazil (2014) Protective and risk factors for chronic diseases by telephone survey. IOP Publishing Physics Web. http://biavati.files.wordpress.com/2014/05/vigitel-2013.pdf (accessed September 2014).

5. Miura K, Greenland P, Stamler J, et al. (2004) Relation of vegetable, fruit, and meat intake to 7-year blood pressure change in middle-aged men: the Chicago Western Electric Study. Am J Epidemiol 159, 572-580.

6. Odegaard AO, Jacobs JR, Steffen LM, et al. (2013) Breakfast frequency and development of metabolic risk. Diabetes Care 36, 3100-3106.

7. Appel LJ, Moore TJ, Obarzanek E, et al. (1997) A clinical trial of the effects of dietary patterns on blood pressure. DASH Collaborative Research Group. N Engl J Med 336, 1117-1124.

8. Tsubota-Utsugi M, Ohkubo T, Kikuya M, et al. (2011) High fruit intake is associated with a lower risk of future hypertension determined by home blood pressure measurement: the OHASAMA study. J Hum Hypertens 25, 164-171.

9. Timlin MT \& Pereira MA (2007) Breakfast frequency and quality in the etiology of adult obesity and chronic diseases. Nutr Rev 65, 268-281.

10. Leidy HJ, Armstrong CL, Tang M, et al. (2010) The influence of higher protein intake and greater eating frequency on appetite control in overweight and obese men. Obesity (Silver Spring) 18, 1725-1732.

11. Salles-Costa R, Pereira RA, Vasconcellos MTL, et al. (2008) Association between socioeconomic factors and food insecurity: a population-based study in the Rio de Janeiro metropolitan area, Brazil. Rev Nutr 21, 99-109 (Portuguese).

12. Popkin BM (2011) Contemporary nutritional transition: determinants of diet and its impact on body composition. Proc Nutr Soc 70, 82-91.

13. Lang T \& Heasman M (2004) Food Wars: The Global Battle for Mouths, Minds and Markets. London: Earthscan. http:// ir.nmu.org.ua/bitstream/handle/123456789/127741/1c5e637f 1bb930158da929aba2a7b2b4.pdf?sequence $=1 \quad$ (accessed November 2015)

14. Castillo DC, Ramsey NL, Yu SS, et al. (2012) Inconsistent access to food and cardiometabolic disease: the effect of food insecurity. Curr Cardiovasc Risk Rep 6, 245-250.

15. Seligman HK, Laraia BA \& Kushel MB (2010) Food insecurity is associated with chronic disease among low-income NHANES participants. J Nutr 140, 304-310.

16. Monteiro CA (2003) The extent of poverty, malnutrition and hunger in Brazil: implications for public policy. National
Institute of Advanced Studies. Special Seminar of Hunger and Poverty. IOP Publishing PhysicsWeb. http://forumnacional. org.br (accessed July 2014).

17. Haldane JBS (1945) On a method of estimating frequencies. Biometrika 33, 222-225.

18. Lohman TG, Roche AF \& Martorell R (1988) Anthropometric Standardization Reference Manual. Champaign, IL: Human Kinetics Books.

19. World Health Organization (2004) Obesity: Preventing and Managing the Global Epidemic. WHO Technical Report Series no. 894. Geneva: WHO.

20. Ntuli ST, Maimela E, Alberts M, et al. (2015) Prevalence and associated risk factors of hypertension amongst adults in a rural community of Limpopo Province, South Africa. Afr J Prim Health Care Fam Med 7, 1-5.

21. Lessa I (2001) Epidemiologia da insuficiência cardíaca e da hipertensão arterial sistêmica no Brasil (Epidemiology of arterial hypertension and heart failure in Brazil). Rev Bras Hipertens 8, 383-392.

22. Senicato C \& Barros MB (2012) Social inequality in health among women in Campinas, Sao Paulo State, Brazil. Cad Saude Publica 28, 1903-1914.

23. Dórea LE \& Lotufo PA (2004) Epidemiologia da hipertensão arterial sistêmica (Hypertension epidemiology). Hipertens $\mathbf{7}$, 86-89.

24. Piccini RX, Facchini LA, Tomasi E, et al. (2012) Promotion, prevention and arterial hypertension care in Brazil. Rev Saúde Pública 46, 543-550.

25. Brazilian Association of Market Research Institutes (2011) Brazilian Standard of socioeconomic classification. IOP Publishing PhysicsWeb. http://www.abep.org/new/criterioBrasil.aspx (accessed July 2014).

26. Segall-corrêa AM, Marin-león L, Melgar-quinonez $\mathrm{H}$, et al. (2014) Refinement of the Brazilian Household Food Insecurity Measurement Scale (EBIA): recommendation for a 14-item EBIA. Rev Nutr 27, 241-251.

27. Halperin RO, Gaziano JM \& Sesso HD (2008) Smoking and the risk of incident hypertension in middle-aged and older men. Am J Hypertens 21, 148-152.

28. Thadhani R, Camargo CA Jr, Stampfer MJ, et al. (2002) Prospective study of moderate alcohol consumption and risk of hypertension in young women. Arch Intern Med 162, 69-574.

29. Census Bureau (2005) CSPRO: Census and Survey Processing System. Version 2.3. Washington, DC: Census Bureau.

30. Stata (2011) Data Analysis and Statistical Software. Version 13.0. College Station, TX: Stata Corporation.

31. Chobanian AV, Bakris GL, Black HR, et al. (2003) Seventh report of the Joint National Committee on prevention, detection, evaluation, and treatment of high blood pressure. Hypertension 42, 1206-1252.

32. Ulbrich AZ, Bertin RL, Neto AS, et al. (2011) Association of the nutritional status with hypertension in adults. Motriz 17, 424-430.

33. Binia A, Jaeger J, Hu Y, et al. (2015) Daily potassium intake and sodium-to-potassium ratio in the reduction of blood pressure: a meta-analysis of randomized controlled trials. J Hypertens 33, 1509-1520.

34. Griep LMO, Stamler J, Chan Q, et al. (2013) Association of raw fruit and fruit juice consumption with blood pressure: the INTERMAP study. Am J Clin Nutr 97, 1083-1091.

35. Darmon N, Ferguson E \& Briend A (2003) Do economic constraints encourage the selection of energy dense diets? Appetite 41, 315-322

36. Darmon N, Ferguson El \& Briend A (2002) A cost constraint alone has adverse effects on food selection and nutrient 
density: an analysis of human diets by linear programming. J Nutr 132, 3764-3771.

37. Drewnowski A, Darmon N, Ferguson E, et al. (2004) Replacing fats and sweets with vegetable and fruits a question of cost. Am J Public Health 94, 1555-1559.

38. Claro RM \& Monteiro CA (2010) Family income, food prices, and household purchases of fruits and vegetables in Brazil. Rev Saúde Pública 44, 1014-1020.

39. Ministry of Health (Brazil) (2004) Dietary Guidelines for the Brazilian Population, 2nd ed. Brasília: Ministry of Health.

40. Klok MD, Jakobsdottir S \& Drent ML (2007) The role of leptin and ghrelin in the regulation of food intake and body weight in humans: a review. Obes Rev 8, 21-34.

41. Holmbäck I, Ericson U, Gullberg B, et al. (2010) A high eating frequency is associated with an overall healthy lifestyle in middle-aged men and women and reduced likelihood of general and central obesity in men. Br J Nutr 104, 1065-1073.

42. Astbury NM, Taylor MA \& Macdonald IA (2011) Breakfast consumption affects appetite, energy intake, and the metabolic and endocrine responses to foods consumed later in the day in male habitual breakfast eaters. J Nutr 141, 1381-1389.

43. Leidy HJ, Ortinau LC, Douglas SM, et al. (2013) Beneficial effects of a higher-protein breakfast on the appetitive, hormonal, and neural signals controlling energy intake regulation in overweight/obese, 'breakfast-skipping,' lateadolescent girls. Am J Clin Nutr 97, 677-688.

44. Levitsky DA \& Pacanowski CR (2013) Effect of skipping breakfast on subsequent energy intake. Physiol Behav 119, 9-16.

45. Sarno FM, Claro R, Bertazzi L, et al. (2013) Estimated sodium intake for the Brazilian population, 2008-2009, 2008-2009. Rev Saúde Pública 47, 571-578.
46. Araujo MC, Bezerra IN, Barbosa FS, et al. (2013) Macronutrient consumption and inadequate micronutrient intake in adults. Rev Saúde Pública 47, 177s-189s.

47. McLean RM (2014) Measuring population sodium intake: a review of methods. Nutrients $\mathbf{6}, 4651-4662$.

48. López Díaz-Ufano ML (2015) Consumption estimation of non alcoholic beverages, sodium, food supplements and oil. Nutr Hosp 26, 70-75.

49. Martínez-González MA, de la Fuente-Arrillaga C, López-Del-Burgo C, et al. (2011) Low consumption of fruit and vegetables and risk of chronic disease: a review of the epidemiological evidence and temporal trends among Spanish graduates. Public Health Nutr 14, 2309-2315.

50. Souza AM, Bezerra IN, Pereira RA, et al. (2013) Dietary sources of sodium intake in Brazil in 2008-2009. J Acad Nutr Diet 113, 1359-1365.

51. Turi BC, Codogno JS, Fernandes RA, et al. (2016) Low levels of physical activity and metabolic syndrome: cross-sectional study in the Brazilian public health system. Cien Saude Colet 21, 1043-1050.

52. Sá Silva SP, Sandre-Pereira G \& Salles-Costa R (2011) Fatores sociodemográficos e atividade física de lazer entre homens e mulheres de Duque de Caxias/RJ (Sociodemographic factors and leisure physical activity among men and women of Duque de Caxias-RJ-Brazil). Ciênc Saude Colet 16, 4491-4501.

53. Shariff ZM, Sulaiman N, Jalil RA, et al. (2014) Food insecurity and the metabolic syndrome among women from low income communities in Malaysia. Asia Pac J Clin Nutr 23, 138-147. 